\title{
HABITAÇÃO DE INTERESSE SOCIAL: AS TIPOLOGIAS HABITACIONAIS E O SEU REFLEXO NA PRODUÇÃO DA CIDADE ATRAVÉS DO PROGRAMA MINHA CASA MINHA VIDA
}

\author{
Gustavo Favaretto Martinez, Marcelo Batista Pigioni, Mayra Martins Brunelli, Cristina Maria \\ Perissinotto Baron
}

Arquitetura e Urbanismo - Departamento de Planejamento, Urbanismo e Ambiente-Faculdade de Ciências e Tecnologia - FCT-UNESP-Campus Presidente Prudente / favarettomartinez@gmail.com

\section{RESUMO}

O Programa Minha Casa Minha Vida - MCMV é, sem dúvida, uma proposta audaciosa do ponto de vista numérico, pretendendo-se chegar até 2014 a um total de três milhões de moradias construídas. $\mathrm{O}$ seu lançamento está ligado a uma tentativa de enfrentamento da crise econômica mundial nos anos 2008/09, no qual o Governo Federal, além de reduzir o déficit habitacional, viu a possibilidade de fortalecer o setor da construção civil. Devido ao programa MCMV e ao impulso a construção civil, o Brasil assiste hoje a uma grande mudança em suas cidades, que crescem de forma desordenada, ocasionando novos problemas urbanos. Além dos problemas urbanos, outra questão frequentemente levantada é a qualidade das unidades habitacionais produzidas, as quais continuam reproduzindo modelos já superados e apresentando problemas construtivos. Este trabalho discute as questões da produção formal de conjuntos habitacionais, as tipologias das unidades, e os possíveis impactos na malha urbana existente.

Palavras-chave: Programa Minha Casa Minha Vida, déficit habitacional, conjuntos habitacionais, habitação de interesse social, políticas habitacionais.

\section{INTRODUÇÃO}

Após um longo período de estagnação das políticas habitacionais para a população de baixa renda, o Governo Federal lança, em 2009, o programa "Minha Casa, Minha Vida" (MCMV), que caracteriza-se como uma importante ferramenta social, motivo pelo qual o Governo tentou, ao máximo, facilitar a participação de interessados na aquisição da casa própria. Em suma, o programa visa a redução do déficit habitacional nacional, através da construção de uma grande quantidade de unidades habitacionais, voltadas a população com renda mensal de até dez salários mínimos, priorizando a faixa com até três salários mínimos, reforçando seu cunho social.

O presente trabalho tem como objetivo, mostrar de forma clara e objetiva os aspectos do programa "Minha Casa, Minha Vida" ("MCMV"), apresentando as informações básicas sobre este, seus participantes, sua sistemática, exemplos de empreendimentos voltados para as famílias que possuem renda até três salários mínimos, e seu reflexo na cidade em que é implantado, mais especificamente, na cidade de Presidente Prudente, localizada na região Oeste do estado de São Paulo. 


\section{METODOLOGIA}

A pesquisa teve como métodos a pesquisa bibliográfica sobre a temática de habitação de interesse social, o levantamento de empreendimentos produzidos pelo programa "Minha Casa, Minha Vida", e o levantamento da localização dos empreendimentos realizados no município de Presidente Prudente, para a faixa de mais baixa renda.

\section{O PROGRAMA MINHA CASA, MINHA VIDA}

O programa "Minha Casa, Minha Vida" foi instituído em março de 2009, no segundo mandato do presidente Luiz Inácio Lula da Silva. Pode-se dizer que se trata do maior programa habitacional realizado no Brasil, após o fechamento do Banco Nacional de Habitação - BNH. O país passou por um longo período após 1986, com programas municipais estaduais, que não reduziram de forma significativa o déficit habitacional, haja visto a estagnação, pela qual passou nos anos 90 , no governo de Fernando Henrique Cardoso.

O programa MCMV é coordenado pela Caixa Econômica Federal (CEF), e tem como principal objetivo a redução significativa do déficit habitacional brasileiro. Trata-se, portanto, de um programa de cunho social. Para Bonduki (2012), o objetivo principal deste programa, era enfrentar a crise econômica de 2008/9 investindo-se recursos no setor da construção civil. A meta do MCMV é de construir 3 milhões de moradias populares até o ano de 2014, sanando, desta forma, cerca de $53 \%$ do déficit habitacional do país.

A primeira fase do programa ocorreu entre 2009 e 2011 e produziu 1,3 milhões de unidades habitacionais, já a segunda fase vai de 2011 a 2014 e possui a meta de construir mais 1,7 milhões de habitações.

Para a implementação do MCMV foi necessária a participação de outras instituições, inclusive da iniciativa privada. Desta forma, participam do programa a Caixa Econômica Federal $\mathrm{CEF}$, como instituição financeira responsável pela definição dos critérios técnicos necessários a operacionalização do programa. O Ministério das Cidades, da Fazenda e do Planejamento, que juntos são responsáveis por determinar as regras, diretrizes e condições da distribuição dos recursos entre os estados federados, bem como acompanhar e avaliar os trabalhos desenvolvidos para o programa.

Estados, Distrito Federal e Municípios se comprometem a estabelecer e criar meios facilitadores para a implementação dos projetos, indicando as áreas com prioridade, e a demanda de solicitantes. 
E por fim, as empresas da construção civil, vistas por muitos como as maiores beneficiarias do programa, e a população alvo, que são atendidas separadas em duas faixas de renda: famílias com renda mensal bruta de até 3 salários mínimos ( $R \$ 1.600,00)$ e famílias com renda mensal bruta de 4 a 10 salários mínimos $(R \$ 5.000,00)$.

Quanto a abrangência, apesar de se tratar de um programa nacional, o MCMV sofre restrições quanto a localização de seus empreendimentos devido ao parâmetro do contingente populacional local. São atendidos pelo programa: Capitais estaduais e suas respectivas regiões metropolitanas, o Distrito Federal e municípios com população igual ou superior a 50 mil habitantes.

O programa estipula que para as famílias com renda mensal de até 3 salários mínimos o menor valor das parcelas do imóvel deve ser de $\mathrm{R} \$ 25,00$. O financiamento pode ser feito em até 120 prestações, e a parcela não pode comprometer mais do que $5 \%$ da renda familiar. No início do programa estipulou que os valores das moradias seguiriam a valoração, sempre de acordo com o número de habitantes da cidade: $\mathrm{R} \$ 80.000,00$ para cidades com até 250 mil de habitantes; $\mathrm{R} \$$ 100.000,00 para cidades com até 500 mil de habitantes; $R \$ 130.000,00$ para cidades com até 1 milhão de habitantes. Estes valores não vem sendo seguidos, o que se vê hoje, em 2013, são valores bem maiores, com casas comercializadas a $\mathrm{R} \$ 120.000,00$ em cidades com até 250.000 habitantes, como é o caso de Presidente Prudente no interior de São Paulo, com população de 207.000 habitantes.

Com relação ao seu funcionamento, o "Minha Casa, Minha Vida" tem sistemática própria e relativamente simples. Para que os empreendimentos sejam implantados em uma determinada região, o governo estadual, ou o município interessado, deve firmar um Termo de Adesão com a Caixa Econômica Federal. Uma vez firmado, a CEF passa a receber as propostas de aquisição de terreno, ou de requalificação de empreendimentos para análise, juntamente com a documentação necessária descriminada por ela. Uma vez analisada e aprovada a proposta, a Caixa Econômica contrata a operação, faz o acompanhamento das obras realizadas pela construtora habilitada, e destina os imóveis à população alvo.

\section{DISCUSSÃO}

Para a faixa de renda de até três salários mínimos, destinam-se, na grande maioria das vezes, os empreendimentos do tipo casa térrea, porém também são executados apartamentos. Ambas as tipologias devem ser adquiridas na planta. Quando a família enquadra-se nessa faixa de 
renda mensal bruta, e nenhum de seus membros possuí um imóvel em seu nome, ela deve procurar a Prefeitura de seu município, e efetuar seu cadastro no programa. No entanto, somente esses dois quesitos não garantem que esta família será beneficiada. A Lei № 11.997, de 7 de junho de 2009, que dispõe sobre os parâmetros de priorização e o processo de seleção dos beneficiários do Programa "Minha Casa, Minha Vida" - MCMV, traz aos critérios nacionais para a seleção dos candidatos, que são: a) Famílias residentes em áreas de risco ou insalubres ou que tenham sido desabrigadas; b) Famílias com mulheres responsáveis pela unidade familiar; e c) Famílias de que façam parte pessoas com deficiência.

Além dos critérios nacionais, a lei em questão prevê que o Distrito Federal, estados, municípios e entidades organizadoras poderão estabelecer até três critérios adicionais de seleção, sendo estes de territorialidade ou de vulnerabilidade social, priorizando, desta forma, candidatos que habitam ou trabalham próximos à região do empreendimento, de forma a evitar deslocamentos intraurbanos extensos, ou que se encontrem em situação de rua e recebam acompanhamento sócio assistencial.

Os empreendimentos a serem construídos, possuem especificações técnicas (Portaria 325) e custos pré-definidos pela própria Caixa Econômica Federal, visando estabelecer padrões mínimos e máximos que atendam ao perfil do beneficiário. Entre as especificações destacam-se o limite de até 500 unidades habitacionais para empreendimento horizontal, sendo que a metragem quadrada mínima da unidade habitacional deve ser $35 \mathrm{~m}^{2}$. Enquanto que para os condomínios verticais há o limite de 250 unidades habitacionais, de metragem quadrada mínima de $42 \mathrm{~m}^{2}$. A CEF, também exige que 3\% das unidades habitacionais sejam destinadas a idosos, e outros $3 \%$ das unidades habitacionais - na ausência de percentual superior fixado em legislação municipal ou estadual - sejam destinadas a pessoas com deficiência, ou cuja família façam parte pessoas com deficiência. Apesar deste percentual destinado a estes usuários específicos, todas as casas do empreendimento são adaptáveis. As unidades habitacionais reservadas, que não forem destinadas por falta de demanda, devem ser destinadas aos demais candidatos.

As figuras 1 e 2 mostram a tipologia de uma casa oferecida pelo programa, seguindo os padrões estabelecidos pela Portaria 325. A partir das imagens, nota-se que trata-se de uma edificação de dois dormitórios, uma sala, um banheiro, com a pia para fora deste, o que é interessante, uma pequena cozinha, e o tanque de lavar roupas coberto somente pelo beiral, segundo técnicos da Caixa Econômica Federal este problema foi solucionado na segunda fase do 
MCMV com a especificação de uma cobertura para área do tanque, portanto, esta é uma edificação construída ainda na primeira fase do programa, entre os anos de 2009 a 2011.

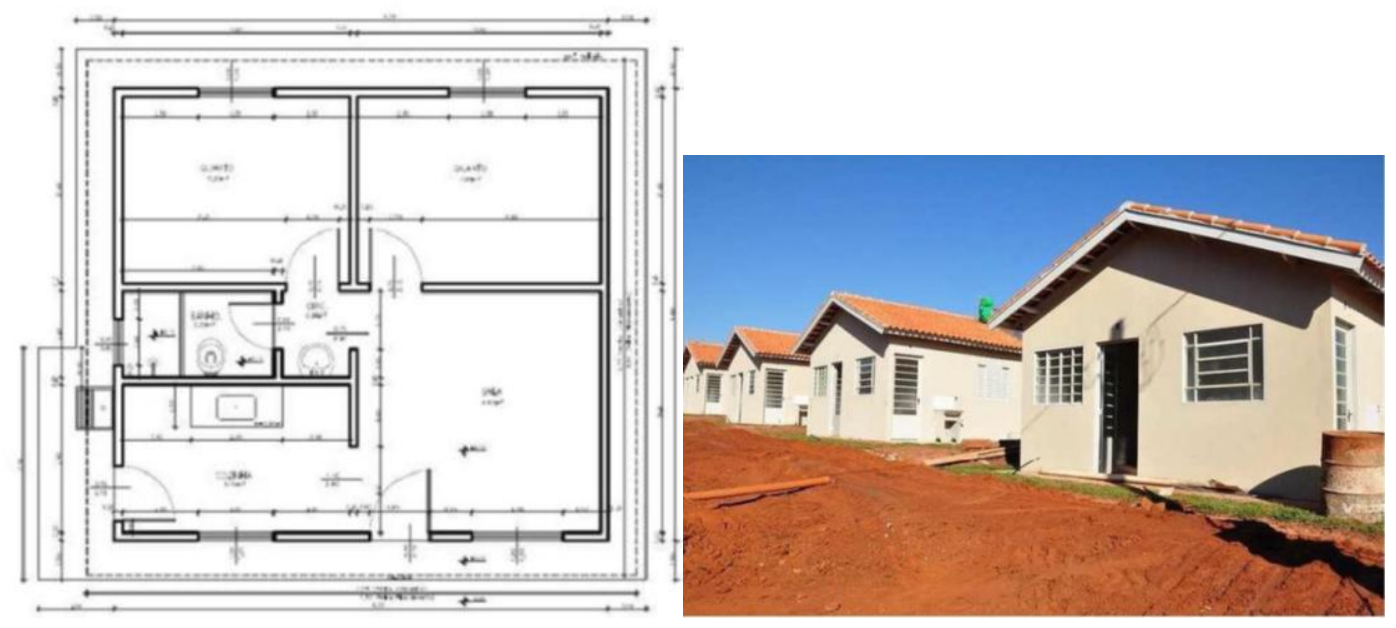

Figura 1 e 2. Casas térreas voltadas as famílias com renda mensal de até 3 salários mínimos. Fonte: DOVAL E BATISTA (2012).

Do mesmo modo que as unidades habitacionais horizontais (casas térreas), as unidades habitacionais verticais, também devem seguir os critérios estabelecidos tanto pela portaria 325 quanto pela CEF, abaixo pode-se observar a fachada de um destes empreendimentos (Figura 3), bem como sua planta baixa (Figura 4). As especificações técnicas, diferem minimamente das especificações das unidades habitacionais térreas.

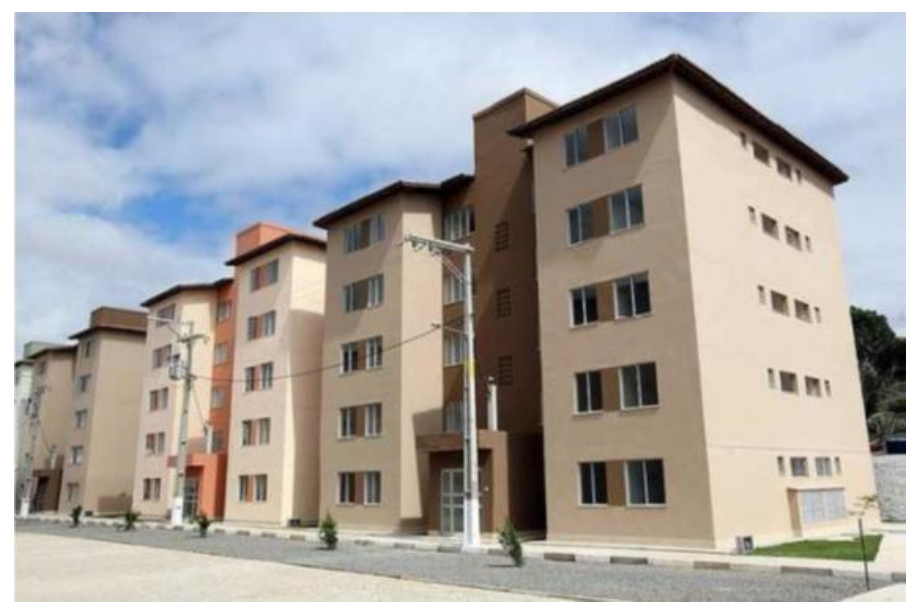

Figura 3. Unidades habitacionais verticais destinadas a famílias com renda mensal de até 3 salários mínimos.

Fonte: DOVAL E BATISTA (2012). 


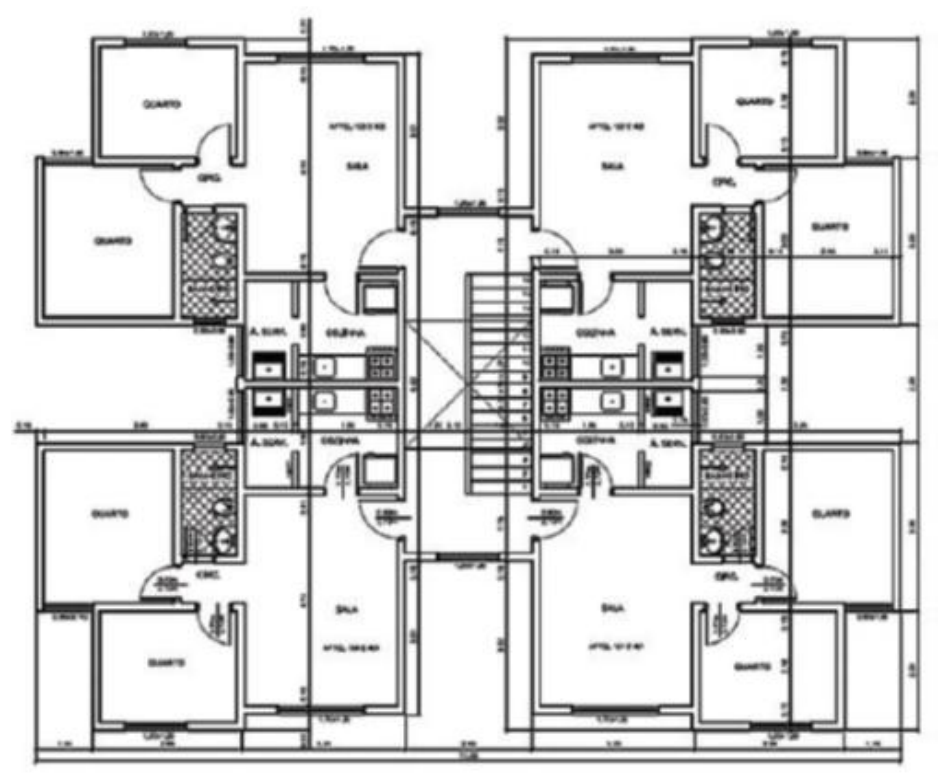

Figura 4. Exemplo de planta para a tipologia de unidade vertical indicada.

Fonte: Portaria 325.

Os dois exemplos mostrados acima são direcionados, como já mencionado, ao público de até três salários mínimos cadastrados nas respectivas prefeituras de seu município. Como a demanda, neste grupo de beneficiários, é maior do que a oferta, muitas vezes só uma pequena parcela dos cadastrados é contemplada com este tipo de habitação. Esta possui um baixo custo, podendo ser resultado de uma parceria entre municípios e construtoras (parceria públicoprivada), onde a prefeitura entra com a área a ser realizado o empreendimento, e uma construtora, contratada por intermédio de licitação, realiza e administra a obra.

Os empreendimentos voltados a este público, não são o foco do trabalho aqui apresentado, no entanto, achou-se necessário citá-los, no intuito de apresentar os modelos tipológicos produzidos para este segmento. A grande maioria unidades comercializadas, para as famílias com renda mensal bruta de 4 a 10 salários mínimos, são em condomínios verticais. Estes podem ser executados e comercializados (visando o lucro), tanto por pequenos construtores em escala local, ou por grandes construtoras, conhecidas nacionalmente que oferecem, praticamente, os mesmos produtos por todo o país, não levando em consideração as peculiaridades climáticas e sociais de cada região. Para demonstrar a semelhança existente entre esses empreendimentos, segue abaixo plantas de duas grandes construtoras (Figuras 5 e 6 ). 


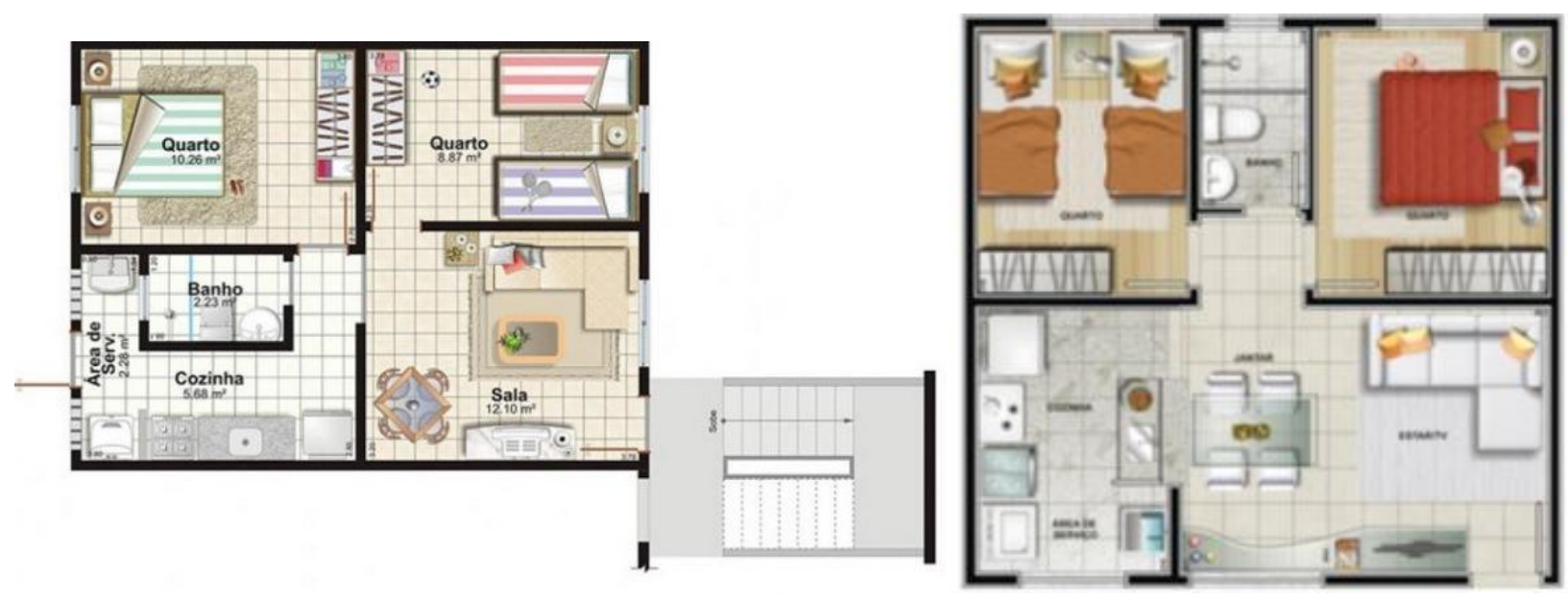

Figuras 5 e 6. Apartamentos de 2 dormitórios, construído e comercializado pela construtora MRV e Construtora Tenda, respectivamente.

A partir das análises anteriores nota-se um padrão estabelecido pelas construtoras em seus empreendimentos. Deve-se atentar-se ao fato de que, a tipologia executada por essas grandes construtoras, nada se difere da tipologia analisada anteriormente, voltada aos beneficiários que se enquadram na categoria de renda mensal até 3 salários mínimos, uma vez que todos possuem em comum 2 dormitórios, somente um banheiro, uma sala, uma cozinha, e uma singela área de serviço, que juntos ocupam uma área inferior a $50 \mathrm{~m}^{2}$.

\section{CONCLUSÕES}

Por fim, devemos também destacar que apesar de todas as boas intenções do programa, que tenta ao menos diminuir o grave problema crônico brasileiro do déficit habitacional, há que se considerar também seus aspectos negativos que ocorrem juntamente com o programa. Em primeiro lugar há o risco de se produzir moradias precárias, que não atendem as necessidades dos proprietários. Isso se deve ao fato de muitas das construtoras priorizarem a quantidade em detrimento da qualidade, além de usarem materiais de baixa qualidade e mão-de-obra não especializada, gerando produtos com falhas técnicas. Em segundo lugar tem-se a baixa aderência ao perfil do déficit prioritário, que é de 1 a 3 salários mínimos, pois há poucas construtoras interessadas nessa faixa, devido a menor rentabilidade.

Em terceiro lugar há especulação imobiliária ocasionada pela abertura de capital de empresas do setor imobiliário e uma forte inversão de capital externo, que iniciou uma avassaladora procura por terrenos, num processo especulativo que chegou a ser chamado, entre 2007 e 2008, de boom imobiliário. 
Finalmente, também a localização dos empreendimentos pode ser inadequada, em áreas carentes de emprego, infraestrutura e equipamentos, gerando, de acordo com Bonduki (2012), novos problemas urbanos, como o agravamento da mobilidade urbana, e a extensão exagerada dos perímetros urbanos. Caso que ocorre na cidade de Presidente Prudente onde os empreendimentos para a faixa até 3 salários mínimos, localizam-se nas regiões periféricas da cidade, na região norte, devido ao menor custo do terreno, promovendo a expansão de seu perímetro urbano, porém, sem planejamento nenhum, uma vez que nas proximidades desses empreendimentos a uma enorme carência de equipamentos institucionais, como creches, escolas e postos de saúde, além pequena quantidade de linhas de transporte público que atendem a esta localidade, dificultando a mobilidade intra-urbana dos moradores.

\section{REFERÊNCIAS}

BONDUKI, N. Do Projeto Moradia ao programa Minha Casa, Minha Vida. Artigo Revista - Teoria e Debate 82 maio/junho 2009,

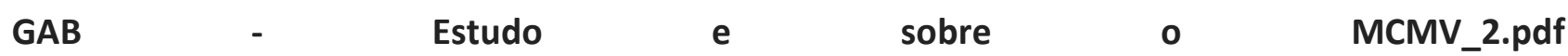
<http://www.almeidalaw.com.br/almeidalaw/upload/noticia/GAB\%20\%20Estudo\%20esobre\%200\%20MCMV 2.pdf> Acesso em junho de 2013.

MINISTÉRIO DAS CIDADES. Gabinete do Ministro. Portaria n. ${ }^{\circ} 610$, de 26 de dezembro de 2011.Dispõe sobre os parâmetros de priorização e o processo de sleção dos beneficiários do Programa Minha Casa Minha Vida-PMCMV. Diário Oficial da União, Brasília, DF, 27 dez. 2011. P. 59 e 60. 